\title{
Effect of High Density Electric Current Pulse on Solidification of Cu-37.4 wt.\%Pb Monotectic Alloy Melt
}

\author{
Teng MA ${ }^{1}$, Guihong GENG ${ }^{2}$, Xiaosi $\mathrm{SUN}^{3}, \mathrm{Xi}_{\mathrm{HAO}}^{4}$, Weixin $\mathrm{HAO}^{5 *}$ \\ ${ }^{1}$ School of Mathematics, Jinzhong University, Jinzhong 030619, Shanxi, China \\ ${ }^{2}$ School of Materials Science and Engineering, North Minzu University, Yinchuan 750000, Ningxia, China \\ ${ }^{3}$ Department of Metallurgy and Environmental Engineering, Shanxi Enginerring Vocational College, Taiyuan 030002, \\ Shanxi, China \\ ${ }^{4}$ The Coordinative Innovation Centre of Taiyuan Heavy Machinery Equipment, Taiyuan University of Science and \\ Technology, Taiyuan 030024, Shanxi, China \\ ${ }^{5}$ School of Materials Science and Engineering, Taiyuan University of Science and Technology, Taiyuan 030024, Shanxi, China \\ crossref http://dx.doi.org/10.5755/j01.ms.26.1.21060
}

Received 27 June 2018; accepted 29 September 2018

\begin{abstract}
The effect of high-density electric current pulse (ECP) on the solidification of $\mathrm{Cu}-37.4 \mathrm{wt} . \% \mathrm{~Pb}$ monotectic alloy melt was investigated. The microstructure formation mechanisms of ECP were clarified according to liquid metal cluster theory. The results demonstrated that with $\mathrm{ECP}$ treatment, the microstructure of $\mathrm{Cu}-\mathrm{Pb}$ monotectic alloy became finer, the distribution of $\mathrm{Pb}$ phase in the matrix was more even and the solute trapping was significantly apparent. Based on the metal liquid cluster theory under ECP, the solid solubility increase result might be due to the salvation clusters increase under the action of pulse current, leading to the binding force increase among solute atoms and solvent atoms. Simultaneously, the aforementioned results were verified through the Differential Scanning Calorimetry (DSC) curve analysis. The results of hardness test, anti-friction test and wear- resistance test show that the ECP can enhance the hardness, improve the properties of anti-friction and wear-resistance of the alloy.

Keywords: electric current pulse, solidification, grain refinement, solid solubility, $\mathrm{Cu}-\mathrm{Pb}$ monotectic alloy.
\end{abstract}

\section{INTRODUCTION}

Due to the excellent wear resistance and superconducting properties, $\mathrm{Cu}-\mathrm{Pb}$ alloys are considered as advanced bearings materials if the soft $\mathrm{Pb}$ phase is dispersed in a hard matrix of $\mathrm{Cu}$ [1]. Adversely, the $\mathrm{Cu}-\mathrm{Pb}$ phase diagram is characterized by the appearance of a miscibility gap in the liquid state $[2,3]$. When a homogeneous liquid is cooled into the miscibility gap, the components are no longer miscible and consequently two liquid phases develop. It is difficult to obtain a uniform and fine alloy structure, severely affecting the material properties of the alloy. A significant amount of research was carried out to investigate this drawback, while the segregation in the solidification structure was avoided through certain techniques, but the progress is still slow due to the higher cost and technological difficulties $[4,5]$.

High-density electric current pulses (ECP) demonstrate high effects on the solidification behaviour. $[6,7]$. The ECP can improve the heterogeneous nucleation rate of a liquid or semi-liquid metal, promoting the solute redistribution and refining the solidification microstructure [8-10]. The effects of ECP treatment on the solidification structure of pure metals $[6,11]$ and eutectic alloys $[5,12]$ were studied in most recent researches. Adversely, the effect of ECP treatment on monotectic alloys has rarely been reported. Simultaneously, many researchers have investigated the solidification microstructure refinement

\footnotetext{
${ }^{*}$ Corresponding author. Tel.: +8613503505572.

E-mail address:wxhao@vip.sina.com (W.X. Hao)
}

through ECP, but few reports exist on the effect of ECP treatment on the solid solubility of alloys. It is generally considered that the liquid structure transition plays an important role to the alloy ingot grain refinement, and many experiments have indicated that the metal casting structure is most closely related to its liquid matrix [13].

In this paper, the solidification microstructure evolution of $\mathrm{Cu}-37.4$ wt.\% $\mathrm{Pb}$ monotectic alloy treated with ECP was investigated. Furthermore, based on liquid metal cluster theory [14], the grain refinement resulting from ECP was studied. Based on the excellent wear resistance of $\mathrm{Cu}-\mathrm{Pb}$ alloy, the hardness test, anti-friction test and wearresistance test of $\mathrm{Cu}-\mathrm{Pb}$ alloy under ECP treatment were carried out. It was proved that the electric pulse can enhance the hardness of $\mathrm{Cu}-37.4 \mathrm{wt} . \% \mathrm{~Pb}$ alloy and improve the properties of anti-friction and wear-resistance of the alloy.

\section{EXPERIMENTAL APPARATUS AND PROCEDURE}

The experimental apparatus consisted of the customized pulse power supply, the vacuum system, the high frequency induction heating device and the temperature measurement system (Fig. 1). In order to reduce heterogeneous nucleation, a customized boron nitride conductive electrode (chemical composition: $\mathrm{BN}+\mathrm{TiB}_{2}+\mathrm{AIN}$ ) of $100 \mathrm{~W} / \mathrm{mk}$ in thermal conductivity was designed and connected to the molybdenum (Mo) electrode (Fig. 2). $\mathrm{Cu}$ and $\mathrm{Pb}$ particles were mixed in a ratio of 
68.6:37.4 ( $\mathrm{Cu}: \mathrm{Pb}$ in wt.\%). These were consequently placed into the cylindrical boron nitride crucible (Fig. 2).

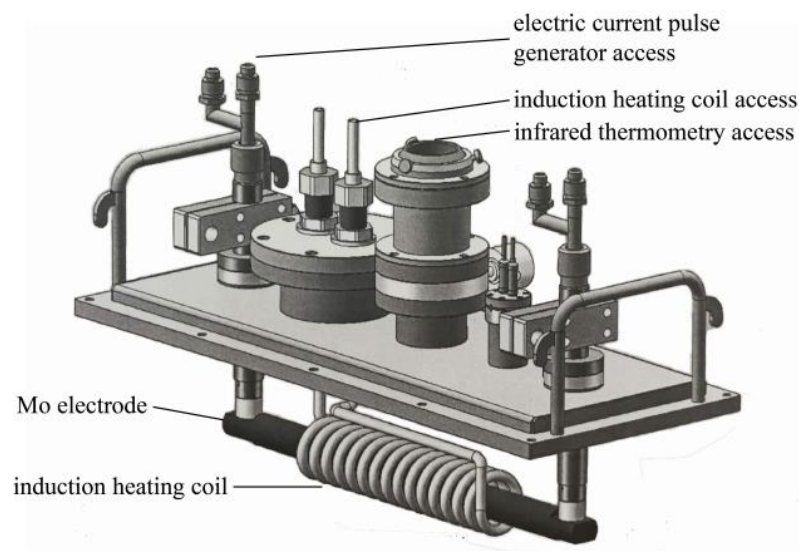

Fig. 1. Schematic drawing of the experimental setup

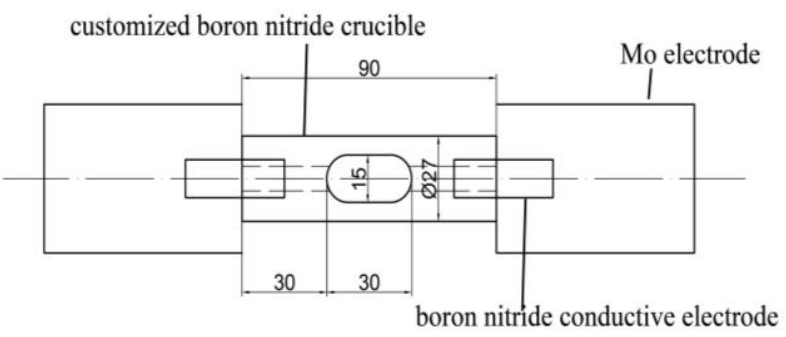

Fig. 2. Schematic sketch of the crucible and the electrodes

Table 1. Parameters of pulsed current

\begin{tabular}{|c|c|c|c|c|}
\hline Sample & $\begin{array}{c}\text { Current } \\
\text { peak, } \mathrm{A}\end{array}$ & $\begin{array}{c}\text { Voltage, } \\
\text { V }\end{array}$ & $\begin{array}{c}\text { Current } \\
\text { frequency, } \mathrm{Hz}\end{array}$ & $\begin{array}{c}\text { Pulse } \\
\text { width, } \mu \mathrm{s}\end{array}$ \\
\hline $\mathrm{a}$ & 800 & 27 & 30 & 20 \\
\hline $\mathrm{b}$ & 1000 & 33 & 30 & 20 \\
\hline $\mathrm{c}$ & 1200 & 40 & 30 & 20 \\
\hline $\mathrm{d}$ & 1400 & 47 & 30 & 20 \\
\hline
\end{tabular}

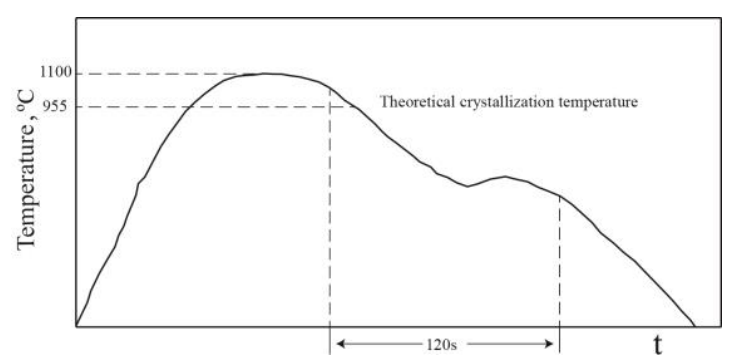

Fig. 3. Schematic diagram of the action time of the ECP on the molten metal

The samples were cyclically overheated to $1200 \mathrm{~K}$ for 5 min under $\mathrm{Ar}$ atmosphere with a high-frequency induction heating device. The ECP treatment was performed when the boron nitride conductive electrode end was horizontally in contact with the molten metal. The parameters of pulsed currents are listed in Table 1. Numerous studies $[15-16]$ had shown that the optimization effect of solidification structure was more significant with the increase of current density, especially in the high-density current conditions, the solidification structure will be greatly improved. For the pulse width, since the high-frequency oscillation attenuation and relaxation time of the low pulse width pulse current were very short, the influence of the Joule heating effect brought about by them can be ignored. Therefore, the current parameters of small pulse width with high frequency were used in this experiment. Where, the current density can be up to $6 \times 10^{6} \mathrm{~A} / \mathrm{m}^{2} \div 2 \times 10^{7} \mathrm{~A} / \mathrm{m}^{2}$ by changing the peak current. Fig. 3 presents the action time schematic diagram of the pulse current on the molten metal.

The effects of ECP on the solidification behavior and phase transition of $\mathrm{Cu}-37.4 \mathrm{wt} . \% \mathrm{~Pb}$ monotectic alloy were analyzed with a TGA/DSC1 synchronous thermal analyzer (Quaintest, FL, USA). Continuous heating and cooling DSC experiments were carried out with an aluminum pan at the rate of $10 \mathrm{~K} / \mathrm{min}$ at the temperature range of room temperature to $1600{ }^{\circ} \mathrm{C}$.

The $10 \mathrm{~mm}$ piece test sample was cut from the solidified specimen and consequently polished for metallographic examination. The etching reagent used to reveal the macrostructure was composed of $80 \%$ of anhydrous alcohol, $10 \%$ of hydrochloric acid and $10 \% \mathrm{w} / \mathrm{v}$ of ferric chloride. The microstructures of $\mathrm{Cu}$ $37.4 \mathrm{wt} \% \mathrm{~Pb}$ monotectic alloys were observed through scanning electron microscopy (SEM) (JSM6510, JEOL, Tokyo, Japan) along the center line of the specimens. Energy dispersive spectroscopy (EDS) tests were performed with an OXFORD X-Max N spectrometer.

The samples prepared at different pulse current peaks were polished and inserted. Hardness was tested by HV120 Vickers hardness tester, with loading load of $5 \mathrm{kgf}$ and loading time of $15 \mathrm{~s}$.

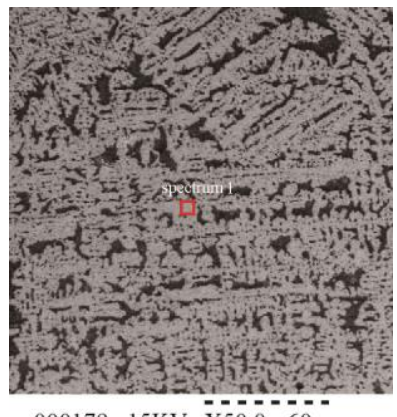

$00017915 \mathrm{KV}$ X $50.0 .60 \mathrm{~mm}$

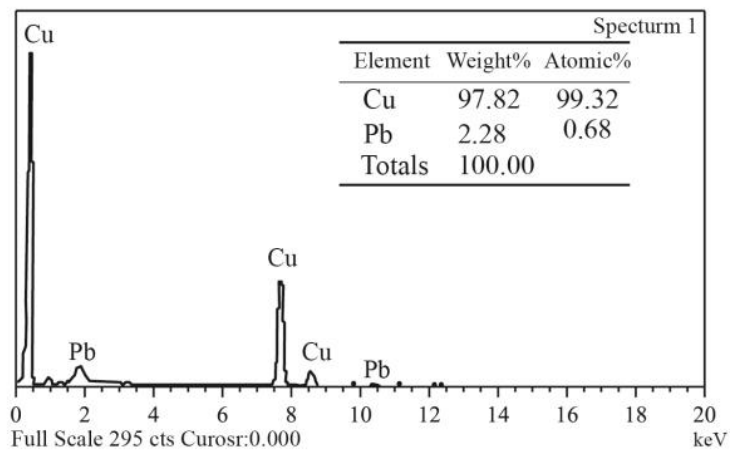

b

Fig. 4. Solidification and the energy spectrum analysis of $\mathrm{Cu}-37.4$ wt.\% Pb monotectic alloys without applied ECP: a-solidification structure; $b$ - energy spectrum analysis 
Under the same conditions, 5 points of the same sample were selected for testing, and the average value was taken as the hardness value of the sample. The friction coefficient and wear rate of $\mathrm{Cu}-37.4 \mathrm{wt} . \% \mathrm{~Pb}$ was tested on SRV friction and wear tester.

\section{RESULTS AND DISCUSSION}

The reference experiment conducted without applied ECP (Fig. 4 a) shows that in solidification of $\mathrm{Cu}-$ 37.4 wt. $\% \mathrm{~Pb}$ alloy, there were coarse dendrites of the
$\alpha(\mathrm{Cu})$ phase and unidirectional solidified structure found, as well as the large $\mathrm{Pb}$ phase distributed between $\alpha(\mathrm{Cu})$ dendrites. The microstructures of $\mathrm{Cu}-37.4 \mathrm{wt} . \% \mathrm{~Pb}$ alloys in the longitudinal section, treated with differential ECPs are presented in Fig. 5. When the ECP treatment with $\mathrm{I}=800 \mathrm{~A}$ was applied, the solidification structure of $\mathrm{Cu}$ $37.4 \mathrm{wt} . \% \mathrm{~Pb}$ monotectic alloys possessed a good overall homogeneity of the microstructures, in which, the $\alpha(\mathrm{Cu})$ dendrites grown at different orientations and their primary arms were relatively tiny.

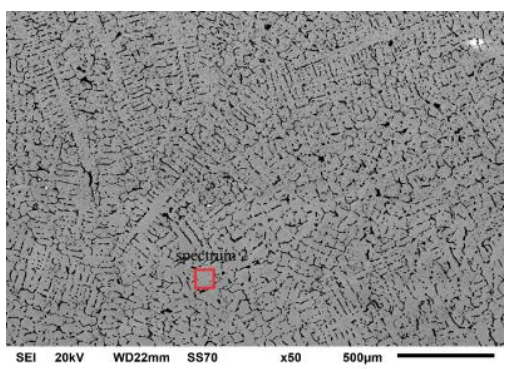

a

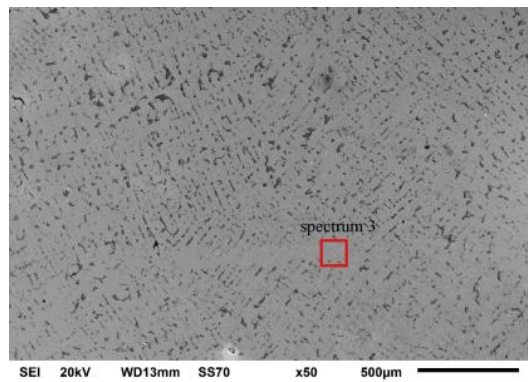

$\mathrm{c}$

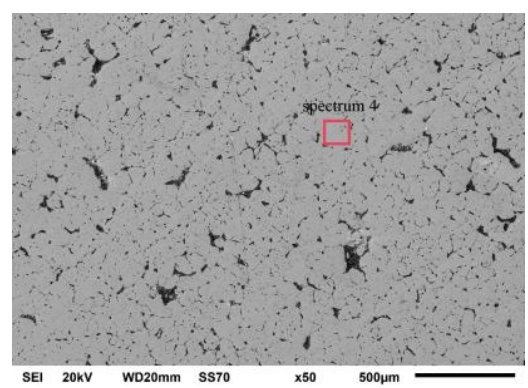

e

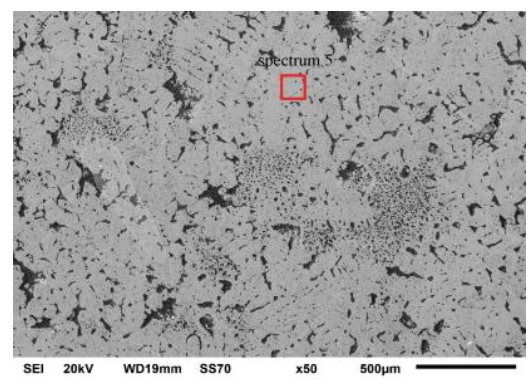

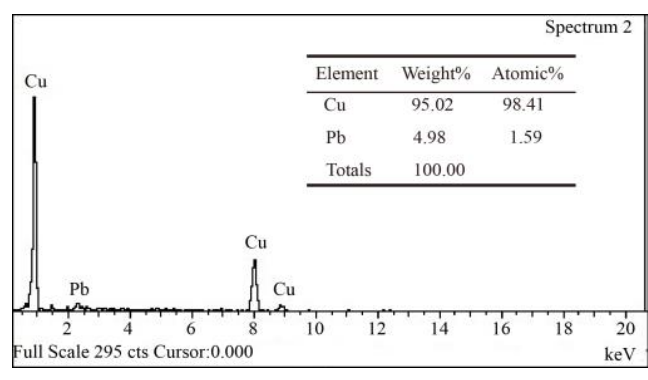

b

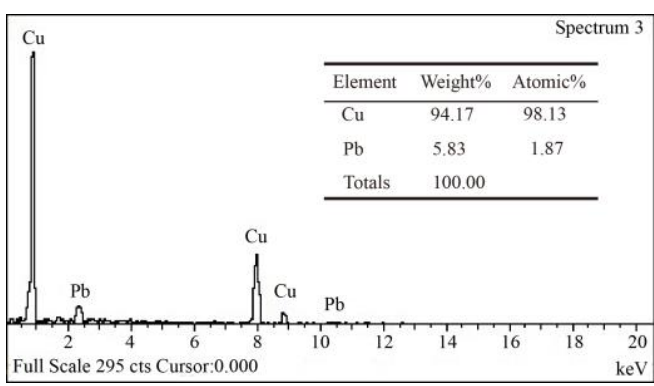

d

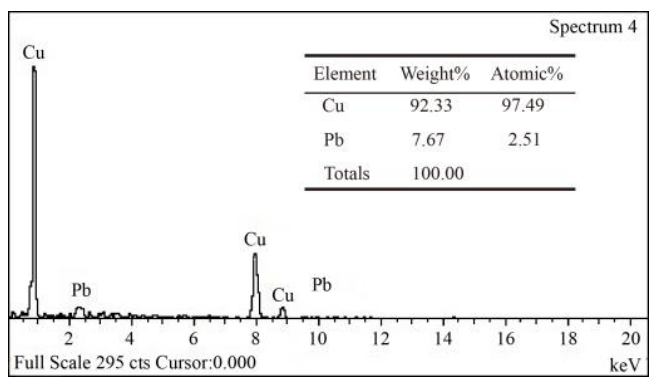

f

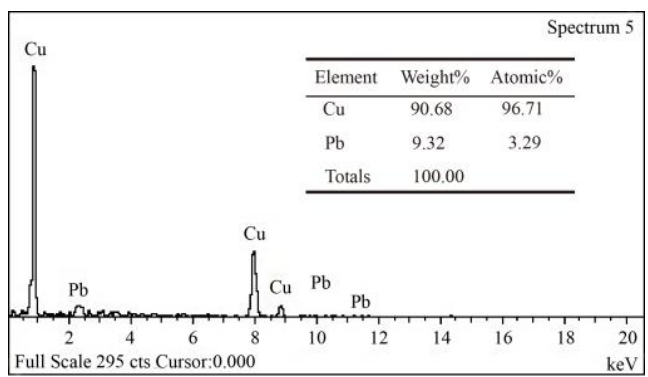

h

Fig. 5. Solidification structure and energy spectrum analysis of alloy structures, treated with different pulse current: $a, b-I=800 A ; c$, $\mathrm{d}-\mathrm{I}=1000 \mathrm{~A} ; \mathrm{e}, \mathrm{f}-\mathrm{I}=1200 \mathrm{~A} ; \mathrm{g}, \mathrm{h}-\mathrm{I}=1400 \mathrm{~A}$ 
Also, the $\mathrm{Pb}$ was dispersed uniformly within the $\alpha(\mathrm{Cu})$ dendrites without visible macro segregation (Fig. 5 a). When the current intensity increased to $\mathrm{I}=1000 \mathrm{~A}$, the solidification structures of $\mathrm{Cu}-37.4 \mathrm{wt} . \% \mathrm{~Pb}$ monotectic alloys were further refined, characterized by shorter primary arms and lower spacing of $\alpha(\mathrm{Cu})$ dendrites (Fig. 5 c). When $\mathrm{I}=1200 \mathrm{~A}$, the solidification structures improved with a certain amount of $\alpha(\mathrm{Cu})$ having transitioned from dendrites to flocculus, along with the dissociation and coagulation of the $\mathrm{Pb}$ phase in $\alpha(\mathrm{Cu})$ dendrites (Fig. 5 e). This demonstrated that an increased amount of the $\mathrm{Pb}$ phase existed in the $\mathrm{Cu}$ matrix. Moreover, low-sized $\mathrm{Pb}$ particles were dispersed in the $\mathrm{Cu}$ matrix, due to solute trapping effects during the rapid solidification.

When the peak current increased up to $1400 \mathrm{~A}$, the flocculent $\mathrm{Pb}$ appeared in the $\mathrm{Cu}$ matrix (shown in Fig. $5 \mathrm{f}$ ), indicating that the solute trapping was more apparent.

Energy spectrum analysis was performed subsequently to the alloy treatment with different pulse currents or without ECP treatment, in order to further investigate the ECP effect on the solidification structures of the $\mathrm{Cu}$ 37.4 wt. $\% \mathrm{~Pb}$ monotectic alloy. As presented in Fig. 4 b, the $\alpha(\mathrm{Cu})$ matrix in the solidified structure contained $97.82 \%$ of $\mathrm{Cu}$ and $2.18 \%$ of $\mathrm{Pb}$ without the ECP treatment. Fig. $4 \mathrm{~d}, \mathrm{f}, \mathrm{h}$ and $\mathrm{j}$ presents that the degree of solid solution of solute $\mathrm{Pb}$ in the $\mathrm{Cu}$ matrix increased as the peak current increased. Based on the aforementioned results, it was inferred that the ECP could significantly enhance the solute trapping effect in the solidification structure of the $\mathrm{Cu}-37.4 \mathrm{wt} . \% \mathrm{~Pb}$ monotectic alloy. As the ECP peak value of the gradually increased, the solute trapping effect became more discrete.

The differential scanning calorimetry (DSC) test results of the samples with ECP or without ECP are presented in Fig. 6, which reflected the heating and cooling behavior of the $\mathrm{Cu}-37.4 \mathrm{wt} \% \mathrm{~Pb}$ monotectic alloy, providing more information on the melt structure changes under various conditions. Table 2 presents the thermodynamic function values calculated based on the DSC curve of each sample. In Fig. 6 a, it was noted that the melting temperature of the unmodified sample was $956.3{ }^{\circ} \mathrm{C}$ and according to the specular equation, the latent heat of fusion was $202.1 \mathrm{~J} / \mathrm{g}$ through calculation. Subsequently to different peak currents $(I=800 \mathrm{~A}, \mathrm{I}=1000 \mathrm{~A}, \mathrm{I}=1200 \mathrm{~A}, \mathrm{I}=1400 \mathrm{~A})$, the melting temperatures of the metals were $956.1^{\circ} \mathrm{C}$,
956.3 ${ }^{\circ} \mathrm{C}, 955.8^{\circ} \mathrm{C}$ and $955.7^{\circ} \mathrm{C}$, respectively, with the corresponding calculated latent heat of fusion values of $170.8 \mathrm{~J} / \mathrm{g}, 163.9 \mathrm{~J} / \mathrm{g}, 149.3 \mathrm{~J} / \mathrm{g}$ and $138.5 \mathrm{~J} / \mathrm{g}$. Apparently, compared to the unmodified samples, the melting temperatures of modified samples with different peak currents slightly changed, whereas the latent heat of fusion was significantly reduced. As presented in the cooling curve (Fig. $6 \mathrm{~b}$ ), the solidification temperature of the sample without ECP treatment was $956.3{ }^{\circ} \mathrm{C}$, while the released latent heat of crystal was $210.8 \mathrm{~J} / \mathrm{g}$. The solidification temperatures of the samples with ECP treatment decreased, while the release of latent heat of the crystal was significantly reduced. When the peak currents were $\mathrm{I}=800 \mathrm{~A}, \mathrm{I}=1000 \mathrm{~A}, \mathrm{I}=1200 \mathrm{~A}, \mathrm{I}=1400 \mathrm{~A}$, the released latent heat values of crystallization were $180.4 \mathrm{~J} / \mathrm{g}, 172.6 \mathrm{~J} / \mathrm{g}, 155.3 \mathrm{~J} / \mathrm{g}$ and $147.2 \mathrm{~J} / \mathrm{g}$. As the ECP peak value increased, the release of latent heat of crystallization was reduced. As it could be observed from Fig. $6 \mathrm{~b}$, the undercooling of the melt significantly increased through ECP treatment. Also, as the peak current increased, the undercooling continuously increased. When the peak current value was $1400 \mathrm{~A}$, the $\mathrm{Cu}-\mathrm{Pb}$ alloy melt undercooling degree was $180 \mathrm{~K}$, which was increased by an order of magnitude compared to the previous studies $[12,14]$.

The $\mathrm{Cu}-37.4$ wt.\% Pb monotectic alloy was immiscible. Therefore, the microstructure depended on the liquid-liquid phase transformation in the miscibility gap [1]. The result indicated that ECP treatment might affect the microstructure formations of the alloy and the spatial motions of the precipitated phase droplets of $\mathrm{Pb}$. According to liquid metal cluster theory [12,17], the microstructure formation and the affecting mechanisms of ECP were clarified as follows.

The atoms and metal clusters existed in the metal melt. According to liquid metal cluster theory, when ECP was applied to the metal melt, the potentials of one side of the metal cluster external layer were reduced, due to repeated distortion and relaxation of the external layer of the cluster (the outer layer of the metal cluster would be repeatedly deformed and relaxed, resulting in a decrease in the electric potential of one side of the outer layer). This would lead to the interaction enhancement among the cluster and the surrounding liquid metal atoms, reducing the "barriers" of the combination of atoms and metal clusters, as well as promoting the combination of clusters and surrounding atoms.

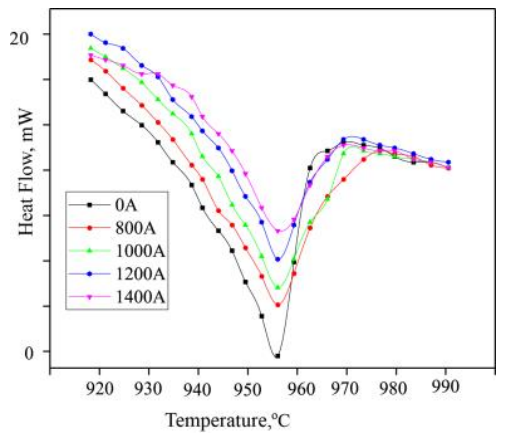

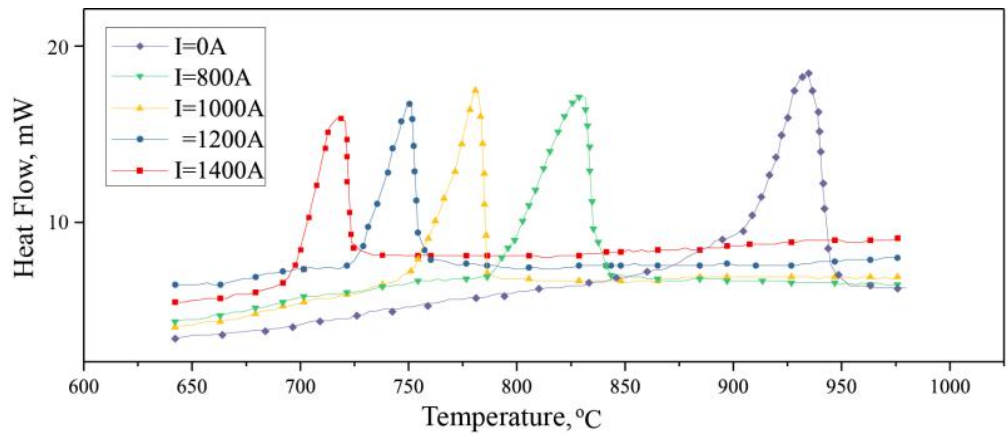

b

Fig. 6. DSC curves of $\mathrm{Cu}-37.4 \mathrm{wt}$.\% Pb alloy with various pulse current peaks: $\mathrm{a}$ - heating curve e; $\mathrm{b}$ - cooling curve 
Table. 3. Differential thermal analysis of $\mathrm{Cu}-37.4 \mathrm{wt} . \% \mathrm{~Pb}$ alloy treated with different pulsed currents

\begin{tabular}{|l|c|c|c|c|c|}
\hline & $\mathrm{I}=0 \mathrm{~A}$ & $\mathrm{I}=800 \mathrm{~A}$ & $\mathrm{I}=1000 \mathrm{~A}$ & $\mathrm{I}=1200 \mathrm{~A}$ & $\mathrm{I}=1400 \mathrm{~A}$ \\
\hline Undercooling, $\mathrm{K}$ & 24.6 & 120.1 & 137.7 & 163.2 & 179.6 \\
\hline Latent heat of fusion, J/g & 202.1 & 170.8 & 163.9 & 149.3 & 138.5 \\
\hline Latent heat of the crystal, J/g & 210.8 & 180.4 & 172.6 & 155.3 & 147.2 \\
\hline Melting temperature, ${ }^{\circ} \mathrm{C}$ & 956.3 & 956.1 & 956.3 & 955.8 & 955.7 \\
\hline Solidification temperature, ${ }^{\circ} \mathrm{C}$ & 930.4 & 834.9 & 817.3 & 791.8 & 775.4 \\
\hline
\end{tabular}

Moreover, the number of large-scale "crystal embryos" that would meet the critical nucleus radius scale would increase, along with the amount of nucleation cores. This would further optimize the solidification structure of the metal $[12,17]$. In the $\mathrm{Cu}-37.4 \mathrm{wt} . \% \mathrm{~Pb}$ alloy melt, the $\mathrm{Cu}$ atoms, the $\mathrm{Pb}$ atoms, the $\mathrm{Cu}-\mathrm{Cu}$ clusters, the $\mathrm{Pb}-\mathrm{Pb}$ clusters and the $\mathrm{Cu}-\mathrm{Pb}$ salvation clusters existed. In liquid alloys, the solvents and solutes have a positive ion effect and a negative ion effect, respectively, due to the difference in electronegativity. According to thermodynamic properties, the salvation clusters were more stable than the solute and solvent clusters [12]. Therefore, when ECP was applied, smaller-scale solvent clusters might form new lower-sized volumes of salvation clusters with solute atoms. As a transformation result, the number of $\mathrm{Cu}-\mathrm{Pb}$ clusters increased, along with the average interaction force among solvent atoms and solute atoms. This resulted in an activity decrease of each component in the metal melt and consequently weakened the segregation during solidification. The activity of the metal melt reflected the ability of the components in the melt to participate in the reaction. Through the ECP treatment, the numbers of dissociated individual atoms in the $\mathrm{Cu}-\mathrm{Pb}$ alloy melt decreased, while most atoms were stable in the form of $\mathrm{Cu}-\mathrm{Pb}$ clusters. It was proved that the ECP improved the solid solubility of the $\mathrm{Cu}-\mathrm{Pb}$ monotectic alloy. Fig. 7 presents a schematic diagram of the alloy melt structure change under the action of ECP.

According to the Miedema formation heat model [18], the equation for the activity is:

$\ln \gamma_{i}=\frac{\alpha_{i j}}{R T}\left[\Delta H_{i j}+\left(1-x_{i}\right) \frac{\partial \Delta H_{i j}}{\partial x_{i}}\right]$,

where $\gamma_{\mathrm{i}}$ is the activity coefficient; $\Delta H_{\mathrm{ij}}$ is the mixing enthalpy; $x \mathrm{i}$ is the molar volume fraction. Eq. 1 presents that the activity coefficients of $\mathrm{Cu}$ and $\mathrm{Pb}$ in the metal melt were related to the mixing enthalpy. According to the metal thermodynamics, the free energy change from one phase to another at a certain temperature is given by [19]:

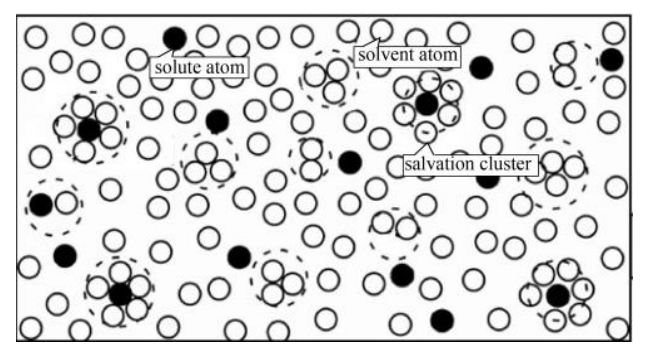

a
$\Delta G=\Delta H-T \Delta S$.

If $\Delta G_{\mathrm{V}}$ for the liquid to solid phase transformation of the free energy change per unit volume, then

$G_{V}=G_{S}-G_{l}$

where $G_{\mathrm{s}}$ and $G_{\mathrm{l}}$ are the unit volume free energy of the solid phase and the unit volume free energy of the liquid phase, respectively, since:

$G=H-T S$.

The $\Delta G_{\mathrm{V}}$ could be expressed as:

$\Delta G_{V}=\left(H_{S}-H_{l}\right)-T\left(S_{S}-S_{l}\right)$

The relationship under the constant pressure conditions is:

$\Delta H_{P}=H_{S}-H_{l}=-L_{m}$,

where $L_{m}$ is the latent heat of fusion, $\Delta H$ is the mixing enthalpy of the melt. Based on the DSC curve presented in Fig. 6 and the calculated result in Table 2, the latent heat of fusion of the sample without ECP treatment was significantly lower compared to the samples with ECP treatments. Also, the latent heat of fusion decreased as the peak value increased. Therefore, under the action of the ECP, the mixing enthalpy of the metal melt decreased, while the activity coefficients of $\mathrm{Cu}$ and $\mathrm{Pb}$ in the metal melt decreased. This signified that the activity of both $\mathrm{Cu}$ and $\mathrm{Pb}$ decreased. The DSC curve confirmed the consistency and rationality of the latter analysis, proving that the ECP treatment increased the solid solubility of metal melt from the thermodynamic point of view.

In metal thermodynamics, the solid-state melting entropy $\Delta S_{m}$ is the melting entropy and it is expressed as [20]:

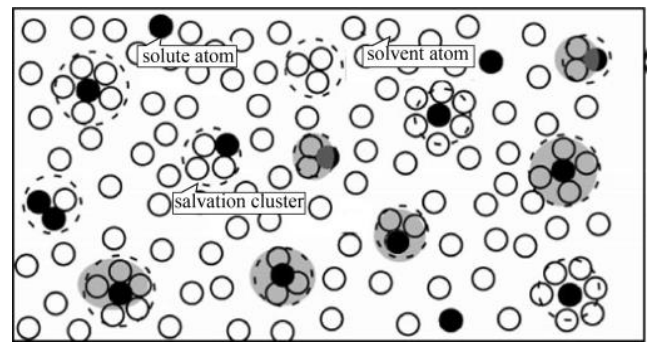

b

Fig. 7. Alloy melt structure transformation under ECP treatment s: $a$-before ECP treatment; $b$-after ECP treatment 
Table. 4. Hardness, friction coefficient and wear rate of $\mathrm{Cu}-37.4$ wt. $\% \mathrm{~Pb}$ alloy treated with different pulsed currents

\begin{tabular}{|c|c|c|c|c|c|}
\hline & $\mathrm{I}=0 \mathrm{~A}$ & $\mathrm{I}=800 \mathrm{~A}$ & $\mathrm{I}=1000 \mathrm{~A}$ & $\mathrm{I}=1200 \mathrm{~A}$ & $\mathrm{I}=1400 \mathrm{~A}$ \\
\hline Hardness, $\mathrm{kgf} \cdot \mathrm{mm}^{-2}$ & 34.3 & 40.5 & 42.7 & 43.4 & 49.3 \\
\hline Friction coefficient & 0.24 & 0.23 & 0.21 & 0.20 & 0.18 \\
\hline Wear rate & 1.3 & 1.0 & 0.9 & 0.7 & 0.4 \\
\hline
\end{tabular}

$$
\Delta S_{m}=S_{S}-S_{l}=-L_{m} / T
$$

This equation reflects the configuration entropy increase when the solid state changes to the liquid phase, while the value is the ratio of latent heat of melting to the melting point. Entropy is actually a measure of disorder. The high entropy represents a high degree of disorder in the melt. According to Fig. 6 and Table 2, it could be concluded that the latent heat of fusion of the sample without ECP treatment was lower compared to the samples with ECP treatment $\left(L_{m}^{\prime}<L_{m}\right)$. Combined with Eq. 7, it could be observed that $\Delta S_{m}^{\prime}$ (with ECP) $<\Delta S_{m}$ (without ECP). The melting entropy decrease of the modified samples indicated that the $\mathrm{Cu}-37.4 \mathrm{wt} . \% \mathrm{~Pb}$ alloy melt disorder degree decreased and the order degree increased. This was consistent with the conclusion that the action of ECP reduced the metal melt activity. It was also proved that with ECP treatment, the solid solubility of the $\mathrm{Cu}$ 37.4 wt.\% Pb monotectic alloy melt was improved. Also, as the peak current increased, the solid solution effect was more apparent.

Viscosity is an important physical quantity, representing the interatomic force and momentum transfer in the liquid metal, also reflecting the binding force and interaction force among atomic groups in the metal melt. Based on the Yokoyama model [20], the following relationships among entropy $S$, diffusion coefficient $D$ and viscosity $\eta$ exist:

$$
D=0.049 \sigma^{2} \exp S \text {; }
$$

$\eta=k_{B} T /(2 \pi \sigma D)$

Subsequently to the ECP treatment, the $\mathrm{Cu}$ 37.4 wt. $\% \mathrm{~Pb}$ alloy entropy decreased, while in combination with Eq. 8 and Eq. 9, it could be inferred that the gold melt viscosity increased. This verified the ECP mechanism to improve the solid solubility of the metal, from the perspective of physical property change of the melt.

Table 4 shows the hardness, friction coefficient and wear rates of $\mathrm{Cu}-37.4$ wt.\% $\mathrm{Pb}$ monotectic alloys which treated with different current peaks. The results show that under the action of pulse current, the hardness of alloy increases, the friction coefficient and the wear rate decreases. As the peak value increases, the properties of anti-friction and wear-resistance of $\mathrm{Cu}-37.4 \mathrm{wt} . \% \mathrm{~Pb}$ alloys were enhanced.

\section{CONCLUSIONS}

The ECP demonstrated a high effect on the microstructure formation of a $\mathrm{Cu}-37.4 \mathrm{wt} . \% \mathrm{~Pb}$ alloy. The ECP treatment could significantly improve the solidification structure of the $\mathrm{Cu}-\mathrm{Pb}$ monotectic alloy, such as with fine microstructure, even distribution of the $\mathrm{Pb}$ phase in the $\mathrm{Cu}$ matrix, along with apparent solute trapping. The solid solubility of $\mathrm{Pb}$ in the $\mathrm{Cu}$ matrix increased. As the ECP peak value gradually increased, the solute trapping effect became more discrete.

According to the metal liquid cluster theory under pulsed electric field, the grain refinement could be a result of the presence of the increasing number of large-scale "embryos" that reached a critical radius; also, the solid solubility increase occurred due to the increase in salvation clusters under the action of pulse current. This led to the binding force increase among solute and solvent atoms.

Through the DSC curve analysis, the decrease in the cluster activity in the alloy melt was verified. The result revealed the mutual action between electric pulse modification and alloy melt structure to a certain extent.

The results of hardness test, anti-friction test and wearresistance test analysis show that the ECP can improve the hardness of $\mathrm{Cu}-37.4 \mathrm{wt} \% \mathrm{~Pb}$ alloy, the properties of antifriction and wear-resistance of the alloy. As the peak value of the pulse current increases, the above properties of the $\mathrm{Cu}-37.4$ wt.\% $\mathrm{Pb}$ alloy are enhanced.

\section{Acknowledgments}

This work was supported by National Natural Science Foundation of China (grant number 51561001 and 51574171) and the Natural Science Foundation of Shanxi Province of China (grant number.201601D011012 and 2015011002).

\section{REFERENCES}

1. Munitz, A., Landau, P., Kaufman, M, Abbaschian, R. Microstructure and Phase Selection in Supercooled Copper Alloys Exhibiting Metastable Liquid Miscibility Gaps Journal of Materials Science 47 2012: pp. 7955-7970. https://dx.doi.org/10.1007/s10853-012-6354-x

2. Molian, P.A., Buchanan, V.E., Sudarshan, T.S., Akers, A. Sliding Wear Characteristics of Non-equilibrium Cu-Pb Alloys Wear 146 1991: pp. 257-267. https://doi.org/10.1016/0043-1648(91)90067-5

3. Buchanan, V.E., Molian, P.A., Sudarshan, T.S., Akers, A. Frictional Behavior of Non-equilibrium $\mathrm{Cu}-\mathrm{Pb}$ alloys Wear 146 1991: pp. 241-256. https://doi.org/10.1016/0043-1648(91)90066-4

4. Samuel, A.M., Garza-Elizondo, G.H., Doty, H.W., Samuel, F.H. Role of Modification and Melt Thermal Treatment Processes on the Microstructure and Tensile Properties of Al-Si Alloys Materials \& Design 80 2015: pp. $99-108$. https://doi.org/10.1016/j.matdes.2015.05.013

5. Tebib, M., Samuel, A.M., Ajersch, F., Chen, X.G. Effect of $\mathrm{P}$ and $\mathrm{Sr}$ Additions on the Microstructure of 
Hypereutectic Al-15Si-14Mg-4Cu Alloy

Materials Characterization 89 (3) 2014: pp. 112-123.

https://doi.org/10.1016/j.matchar.2014.01.005

6. Liao, X., Zhai, Q., Luo, J., Chen, W., Gong, Y. Refining Mechanism of the Electric Current Pulse on the Solidification Structure of Pure Aluminum. Acta Materialia 55 (9) 2007: pp. 3103-3109.

https://doi.org/10.1016/j.actamat.2007.01.014

7. Räbiger, D., Zhang, Y., Galindo, V., Willers, B., Eckert, S. The Relevance of Melt Convection to Grain Refinement in Al-Si Alloys Solidified under the Impact of Electric Currents Acta Materialia 79 (41) 2014: pp. $327-338$. https://doi.org/10.1016/j.actamat.2014.07.037

8. Zhang, Y., Cheng, X., Zhong, H. Comparative Study on the Grain Refinement of Al-Si Alloy Solidified under the Impact of Pulsed Electric Current and Travelling Magnetic Field Metals 6 2016: pp. 170. https://doi.org/10.3390/met6070170

9. Jiang, H., Zhao, J., Wang, C., X, Liu. Effect of Electric Current Pulses on Solidification of Immiscible Alloys Materials Letters 132 2014: pp. 66-69. https://doi.org/10.1016/j.matlet.2014.06.017

10. Ma, J., Li, J., Gao, Y., Jia, L., Li, Z., Zhai, Q. Effect of Peak Value and Discharge Frequency of Electric Current Pulse on Solidification Structure of Fe-1C-1.5Cr Bearing Steel Ironmaking \& Steelmaking 36 (4) 2013: pp. 286-290. https://doi.org/10.1179/174328108x380654

11. Zhao, Z., Su, J., Liu, Y. The Electromagnetic Mechanism of Pulsed Electric Discharge on Directionally Solidified Microstructure of Pure Aluminum Advanced Materials Research 146-147 2011: pp. 297-300. https://doi.org/10.4028/www.scientific.net/amr.146-147.297

12. Wang, J., Qi, J., Zhao, Z., Guo, H., Zhao, T. Effects of Electric Pulse Modification on Liquid Structure of Al-5\% Cu Alloy Transactions of Nonferrous Metals Society of China 23 2013: pp. 2792-2796. https://doi.org/10.1016/s1003-6326(13)62799-5

13. Qi, J., Wang, J., He, L., Zhao, Z., Du, H. An Investigation for Structure Transformation in Electric Pulse Modified Liquid Aluminum Physical B Condensed Matter 406 2011: pp. $846-849$. https://doi.org/10.1016/j.physb.2010.12.010

14. Zhao, Z., Wang, J., Liu, L. Grain Refinement by Pulse Electric Discharging and Undercooling Mechanism Materials and Manufacturing Processes 26 (1) 2011: pp. 249-254. https://doi.org/10.1080/10426914.2010.512649

15. Stepanov, G.V., Babutskii, A.I., Mameev, I.A. HighDensity Pulse Current-Induced Unsteady Stress-Strain State in a Long Rod Strength of Materials 36 (4) 2004: pp. $377-381$. https://doi.org/10.1023/b:stom.0000041538.10830.34

16. Cao, F., Xia, F., Hou, H., Ding, H., Li, Z. Effects of HighDensity Pulse Current on Mechanical Properties and Microstructure in a Rolled Mg-9.3Li-1.79Al-1.61Zn Alloy Materials Science \& Engineering A 637 2015: pp. 89-97. https://doi.org/10.1016/j.msea.2015.03.127

17. Wang, J. Research of Treating Technology with Electropulse Modification and the Hypothesis of Liquid Metal Cluster Structure Ph.D. dissertation University of Science and Technology 1998 Beijing.

18. Miedema, A.R. The Electronegativity Parameter for Transition Metals: Heat of Formation and Charge Transfer in Alloys Journal of The Less-Common Met 32 1973: pp. $117-136$. https://doi.org/10.1016/0022-5088(73)90078-7

19. Wang, J. Effect of ECP Treatment on Solidification Structure and Properties of Nonferrous Metals Beijing (BY): Science Press 2011.

20. Yoloyama, I. Correlation Entropy and its Relation to Properties of Simple Liquid Metals Journal of NonCrystalline Solids 312 (1) 2002: pp. 232-235. https://doi.org/10.1016/s0022-3093(02)01669-1 